\title{
COPD symptom burden: impact on health care resource utilization, and work and activity impairment
}

\author{
Bo Ding' \\ Mark Small ${ }^{2}$ \\ Gina Bergström ${ }^{3}$ \\ Ulf Holmgren ${ }^{3}$
}

'Medical Evidence and Observational Research, AstraZeneca Gothenburg, Mölndal, Sweden; ${ }^{2}$ Real World

Research (Respiratory), Adelphi Real World, Bollington, UK; ${ }^{3}$ Global Payer Evidence and Pricing, AstraZeneca Gothenburg, Mölndal, Sweden
Correspondence: Bo Ding Medical Evidence and Observational Research, Global Medical Affairs, AstraZeneca Gothenburg, Pepparedsleden I, SE-43I 83 Mölndal, Sweden

Tel +46 3I 7762406

Email bo.ding@astrazeneca.com
This article was published in the following Dove Press journal:

International Journal of COPD

21 February 2017

Number of times this article has been viewed

Background: Chronic obstructive pulmonary disease (COPD) can greatly impact the quality of life by limiting patients' activities. However, data on impact of symptomatic burden on the health care resource utilization (HCRU) and employment in COPD are lacking. We examined the association between COPD Assessment Test (CAT) score and direct/indirect costs associated with HCRU and work productivity.

Methods: Data from $>2,100$ patients with COPD consulting for routine care were derived from respiratory disease-specific programs in Europe, the USA and China. Questionnaires, including CAT and Work Productivity and Activity Impairment (WPAI), were used to collect the past and current disease status data and HCRU characteristics from physicians (general practitioners/specialists) and patients. A regression approach was used to quantify the association of CAT with HCRU and WPAI variables. CAT score was modeled as a continuous independent variable (range: 0-40).

Results: Ninety percent of patients with COPD had a CAT score $\geq 10$. Short-acting therapy and maintenance bronchodilator monotherapy, respectively, were currently prescribed to patients with CAT scores of 10-19 (5.8\% and 27.6\%), 20-29 (5.1\% and 13.1\%) and 30-40 $(2.8 \%$ and $6.6 \%)$. Prescribing of maintenance bronchodilator dual therapy was low across the CAT score groups $(0-9,7.8 \% ; 10-19,6.4 \% ; 20-29,5.9 \% ; 30-40,4.4 \%)$, whereas maintenance triple combination therapy was prescribed more commonly in patients with higher CAT scores $(0-9,16.1 \% ; 10-19,23.2 \% ; 20-29,25.9 \% ; 30-40,35.5 \%)$. Increasing CAT scores were significantly associated with a higher frequency of primary care physician visits $(P<0.001)$, pulmonologist visits $(P=0.007)$, exacerbations requiring hospitalization $(P<0.001)$ and WPAI scores $(P<0.001)$.

Conclusion: Most patients with COPD presented with high symptom levels, despite being treated for COPD. Increasing symptom burden was associated with increasing HCRU and had a detrimental impact on work productivity.

Keywords: COPD, symptom, health care resource utilization, work and activity impairment, routine care

\section{Introduction}

Chronic obstructive pulmonary disease (COPD) has a major and growing impact on global health burden. In 2004, COPD accounted for 5.1\% of deaths worldwide, with this proportion expected to rise to $8.6 \%$ by 2030 - in line with the projected increases in tobacco use - making COPD the third leading cause of death. ${ }^{1}$

For the individual patient, COPD imposes important and far-reaching limitations on the activities of daily life. Data derived from the Behavioral Risk Factor Surveillance 
System and analyzed by the US Center for Disease Control and Prevention reveal extensive activity and work limitation among adults self-reporting COPD. ${ }^{2}$ COPD was associated with an almost 5-fold increase in inability to work, a 3-fold increase in activity limitation due to health problems and a $>3$-fold increase in difficulty walking or climbing stairs. For many patients, the cycle is self-perpetuating, with a lack of physical activity fostering ongoing activity limitation in other aspects of daily life. ${ }^{2}$ Activity impairment in COPD is particularly pertinent, given that physical activity is a strong predictor of mortality in COPD patients. ${ }^{3}$

The progression of symptoms and the subsequent reduction in daily activities contribute collectively to a gradual deterioration in the patient's health-related quality of life. ${ }^{4}$ It is not surprising that from the perspective of the patient, the improvement of symptoms and enhancement of ability to engage in the normal activities of daily living (eg, family routine and, if applicable, work) are desirable goals of COPD management. ${ }^{4,5}$

A recent update to the Global Initiative for Chronic Obstructive Lung Disease (GOLD) strategy document placed an increased emphasis on symptom relief in COPD by allowing symptomatic assessment to inform the choice of management strategy. ${ }^{5}$ In order to achieve this, GOLD recommended the use of validated and reliable questionnaires such as the COPD Assessment Test ${ }^{\mathrm{TM}}$ (CAT; GlaxoSmithKline, Brentford, UK) in routine daily clinical practice. The result is a patient assessment system that takes into account both the current impact of a patient's symptoms and their likelihood of having a serious exacerbation - indicative of disease progression - in the future, thereby individualizing the treatment strategy adopted.

A previous study conducted in the USA showed that health care resource utilization (HCRU) and associated costs for a group of 17,382 managed care patients with chronic bronchitis were substantial, despite the use of COPD maintenance medications. The number of baseline exacerbations was a significant predictor of all-cause and COPD-related total costs in this study, but data were not stratified according to symptom severity. ${ }^{6}$ The objectives of our study were: 1) to examine the proportion of patients with COPD who had a symptomatic burden according to CAT score and 2) to explore the association between symptomatic burden (CAT score) and HCRU, and work productivity and activity impairment (WPAI).

\section{Methods}

Data were derived from the disease-specific program (DSP), a survey designed to provide impartial observations of routine clinical practice from a physician and matched patient perspective, with a view to improving standards of care. ${ }^{7}$ Quantitative and qualitative patient and physician data together provide an accurate snapshot of the perception of a particular disease, without preselection of patients. The survey can be viewed as four discrete stages: 1) the screening and recruitment of primary care/specialist physicians; 2) individual interviews with the physicians; 3) the prospective completion, by the physician, of patient record forms for the next consecutive five patients with COPD and 4) the return of patient self-completion records that were completed independently of their physicians. ${ }^{7}$ The Adelphi Respiratory DSPs were surveys conducted in 2010 (China) and 2013 (the USA and Europe) as market research adhering to the International Chamber of Commerce/European Society for Opinion and Marketing Research international code on observational research; therefore, ethics approval was not necessary to obtain and was not sought. Patients provided written informed consent to participate in the survey. All data were anonymized and aggregated prior to receipt by Adelphi Real World.

\section{Study populations}

\section{Patients and physicians}

The patient population comprised adults aged $>40$ years with confirmed airflow obstruction and a diagnosis of COPD consulting for routine care. These criteria included patients with emphysema and chronic bronchitis and excluded patients with a concomitant diagnosis of asthma. Although a COPD diagnosis based on spirometry measurements is desirable, it is acknowledged that this is not always possible or recorded in routine clinical practice. All patients agreeing to participate in the survey completed a questionnaire that included the full CAT questionnaire, with no influence or input from the physician or nurse. Physicians were eligible for participation in the study if they had qualified within the last 5-35 years and were responsible for the treatment of patients with asthma and patients with COPD.

\section{Variables}

Outcome variables were recorded directly by the patient or physician, or were derived from the patient questionnaire. Descriptive variables included age, gender, race, body mass index, smoking status and history, employment status, comorbidities, most recent forced expiratory volume in 1 second $\left(\mathrm{FEV}_{1}, \%\right.$ predicted), current COPD medications and the number of exacerbations in the last 12 months. Physicians also provided HCRU information pertaining 
to the number of patient visits for COPD, either at their practice or elsewhere, and the number of exacerbations requiring hospitalization, within the last 12 months. Patient questionnaire-derived variables included mean CAT score and CAT score range $(0-9,10-19,20-29$ and 30-40) and the WPAI questionnaire. ${ }^{8}$ WPAI data were not collected for patients in the China cohort.

\section{Statistical analyses}

Data were analyzed collectively and as three separate regions: Europe (5EU: France, Germany, Italy, Spain and the UK), China and the USA. All analyses were performed using Stata 13.1 (Stata Statistical Software: release 13; StataCorp LP, College Station, TX, USA).

CAT scores were modeled as a continuous independent variable ranging from 0 to 40 . A regression approach was used to measure the association between CAT scores and WPAI scores or HCRU variables, allowing for the inclusion of confounding variables (eg, age, body mass index, smoking status and history, physician-confirmed diagnosis of depression, anxiety and serious cardiovascular conditions) as covariates. Where the HCRU variable displayed signs of overdispersion, a negative binomial regression model was used. For all other variables, a Poisson regression model was used. For all regression models, the coefficient and $P$-value (Wald test) associated with the CAT variable were used to determine the relationship between CAT and the given HCRU variable or WPAI score.

WPAI assessments included only patients in Europe and the USA who worked full time or part time. Consistent with validated expression of WPAI scores, results were expressed as percentages for four domains: work time missed (absenteeism), work time impaired (presenteeism), overall work impairment (a combination of absenteeism and presenteeism) and total activity impairment. Data were analyzed using an ordinary least square regression model, with the four domains as dependent variables.

\section{Results}

\section{Study population}

Of 4,143 patients with COPD for whom physicians completed patient record forms within the observation period, 2,166 agreed to participate and completed the patient selfcompletion records (Table 1). The largest patient cohorts were from China (23.6\%), the USA (19.1\%) and Germany (16.8\%). The mean (standard deviation [SD]) age of the entire study population was 65.1 (10.7) years; $45.5 \%$ of the population were aged $<65$ years and the majority $(66.6 \%)$
Table I Patient demographics and clinical characteristics

\begin{tabular}{|c|c|c|c|c|}
\hline & Overall & 5EU & USA & China \\
\hline & $\begin{array}{l}(N=2,166, \\
100 \%)\end{array}$ & $\begin{array}{l}(n=1,242, \\
57.3 \%)\end{array}$ & $\begin{array}{l}(n=413 \\
19.1 \%)\end{array}$ & $\begin{array}{l}(n=5 I I, \\
23.6 \%)\end{array}$ \\
\hline \multicolumn{5}{|l|}{$\overline{\text { Age }}$} \\
\hline Missing, n & 0 & 0 & 0 & 0 \\
\hline Mean (SD) & $65.1(10.7)$ & $65.3(10.4)$ & $67.2(9.9)$ & $62.7(11.6)$ \\
\hline \multicolumn{5}{|l|}{ Age, n (\%) } \\
\hline$<65$ years & $985(45.5)$ & $540(43.4)$ & I58 (38.3) & $287(56.2)$ \\
\hline$\geq 65$ years & $\mathrm{I}, \mathrm{I} 8 \mathrm{I}(54.5)$ & $702(56.5)$ & $255(61.7)$ & $224(43.8)$ \\
\hline \multicolumn{5}{|l|}{ Gender, n (\%) } \\
\hline Missing, n & 0 & 0 & 0 & 0 \\
\hline Male & I,442 (66.6) & $896(72.1)$ & $229(55.5)$ & $317(62.0)$ \\
\hline \multicolumn{5}{|l|}{ Race, n (\%) } \\
\hline Missing, $n$ & 4 & 4 & 0 & 0 \\
\hline Caucasian & I,533 (70.9) & $\mathrm{I}, \mathrm{I} 76(95.0)$ & $357(86.4)$ & 0 \\
\hline African & $35(1.6)$ & 0 & $35(8.5)$ & 0 \\
\hline \multicolumn{5}{|l|}{ American } \\
\hline Hispanic & $45(2.1)$ & $33(2.7)$ & $12(2.9)$ & 0 \\
\hline Asian-Indian & $9(0.4)$ & $5(0.4)$ & $4(1.0)$ & 0 \\
\hline \multicolumn{5}{|l|}{ Subcontinent } \\
\hline Asian-other & $9(0.4)$ & $4(0.3)$ & $5(1.2)$ & 0 \\
\hline Chinese & $511(23.6)$ & 0 & 0 & $511(100.0)$ \\
\hline Other & $20(0.9)$ & $20(1.6)$ & 0 & 0 \\
\hline \multicolumn{5}{|l|}{ BMI } \\
\hline Missing, n & 95 & 66 & 28 & I \\
\hline Mean (SD) & $25.6(4.6)$ & $26.0(4.3)$ & $27.5(5.9)$ & $23.3(3.0)$ \\
\hline \multicolumn{5}{|c|}{ Employment status, n (\%) } \\
\hline Missing, $n$ & 38 & 24 & 12 & 2 \\
\hline Employed & $529(24.9)$ & $297(24.4)$ & $118(29.4)$ & II4 (22.4) \\
\hline Retired & $\mathrm{I}, 263(59.4)$ & $713(58.5)$ & $209(52.1)$ & $34 I(67.0)$ \\
\hline Homemaker & $113(5.3)$ & $65(5.3)$ & $23(5.7)$ & $25(4.9)$ \\
\hline Unemployed & $152(7.1)$ & $97(8.0)$ & $26(6.5)$ & $29(5.7)$ \\
\hline On long-term & $71(3.3)$ & $46(3.8)$ & $25(6.2)$ & 0 \\
\hline \multirow{2}{*}{\multicolumn{5}{|c|}{$\begin{array}{l}\text { disability } \\
\text { Smoking status, n (\%) }\end{array}$}} \\
\hline & & & & \\
\hline Missing, $n$ & 11 & I & 2 & 8 \\
\hline Current smoker & $629(29.2)$ & $417(33.6)$ & $132(32.1)$ & $80(15.9)$ \\
\hline Ex-smoker & $\mathrm{I}, 232(57.2)$ & $755(60.8)$ & $260(63.3)$ & $217(43.1)$ \\
\hline Never smoked & $294(13.6)$ & $69(5.6)$ & $19(4.6)$ & $206(41.0)$ \\
\hline \multicolumn{5}{|l|}{ Pack-years } \\
\hline Missing, $n$ & 79 & 48 & 22 & 9 \\
\hline Mean (SD) & $30.0(23.9)$ & $34.9(23.3)$ & $35.1(24.8)$ & $14.7(17.1)$ \\
\hline \multicolumn{5}{|c|}{ Pack-years (grouped), n (\%) } \\
\hline Missing, n & 79 & 48 & 22 & 9 \\
\hline$<10$ & $414(19.8)$ & $136(11.4)$ & $40(10.2)$ & $238(47.4)$ \\
\hline$\geq 10$ & $1,673(80.2)$ & $1,058(88.6)$ & $35 I(89.8)$ & $264(52.6)$ \\
\hline \multicolumn{5}{|c|}{ Most recent FEV test score (post-bronchodilator), \% predicted } \\
\hline Missing, $n$ & 1,287 & 657 & 251 & 379 \\
\hline Mean (SD) & $61.9(18.2)$ & $64.0(18.1)$ & $62.1(17.3)$ & $52.0(16.9)$ \\
\hline \multicolumn{5}{|c|}{ Mean number of exacerbations treated with OCS, antibiotics, } \\
\hline \multicolumn{5}{|c|}{ both, ED or hospitalization in the last 12 months (5EU + US only) } \\
\hline Missing, $n$ & 536 & 16 & 9 & 511 \\
\hline Mean (SD) & $1.3(1.7)$ & $1.3(1.6)$ & $1.2(1.8)$ & - \\
\hline \multicolumn{5}{|c|}{ Frequency of exacerbations treated with OCS, antibiotics, both, } \\
\hline \multicolumn{5}{|c|}{ ED or hospitalization in the last 12 months (5EU + US only), $n$ (\%) } \\
\hline Missing, $n$ & 536 & 16 & 9 & 511 \\
\hline 0 & $728(44.7)$ & $518(42.3)$ & $210(52.0)$ & - \\
\hline I & $320(19.6)$ & $253(20.6)$ & $67(16.6)$ & - \\
\hline 2 & $284(17.4)$ & $224(18.3)$ & $60(14.9)$ & - \\
\hline$\geq 3$ & $298(18.3)$ & $23 \mid(18.8)$ & $67(16.6)$ & - \\
\hline
\end{tabular}

Abbreviations: 5EU, France, Germany, Italy, Spain and the UK; BMI, body mass index; ED, emergency department; $\mathrm{FEV}_{1}$, forced expiratory volume in I second; OCS, oral corticosteroid; SD, standard deviation. 
were male. While the majority of the population were retired (59.4\%), nearly a quarter of them were still engaged in active employment $(24.9 \%)$. Most patients were current or ex-smokers (29.2\% and 57.2\%, respectively). The overall population had a mean (SD) number of 30.0 (23.9) pack-years, and the majority of patients had $\geq 10$ pack-years $(80.2 \%)$. A considerable number of patients surveyed (27.2\%) had a serious concomitant cardiovascular condition. The most frequently occurring comorbidities in this patient population included hypertension (55.8\%), elevated cholesterol (27.0\%) and diabetes (15.5\%; Table S1).

\section{Clinical characteristics}

For the entire study population, the mean most recent postbronchodilator $\mathrm{FEV}_{1}$ was $61.9 \%$ of the predicted value (Table 1). Among patients surveyed in Europe and the USA, $35.7 \%$ had experienced $\geq 2$ exacerbations in the last 12 months that required treatment with oral corticosteroids and/or antibiotics, emergency department (ED) treatment and/or admission to hospital (Table 1).

\section{CAT scores}

Among the three regions studied, the mean (SD) CAT score was highest for China (24.4 [6.1]) and similar for Europe (20.5 [8.3]) and the USA (20.3 [8.7]; Figure 1). Of the entire study population, $90.4 \%$ had a mean CAT score of $\geq 10$ and $62.3 \%$ had a mean CAT score of $\geq 20$. Almost all $(98.2 \%)$ of the patients surveyed in China had a mean CAT score of $\geq 10$ (Figure 1 ).

\section{Treatment by CAT score}

Treatment with single short-acting therapy (not specified as rescue or maintenance medication) was currently prescribed to $5.9 \%$ of patients overall (Table 2 ). In each region, a greater proportion of patients with a CAT score of 0-9 were prescribed single short-acting therapy, compared with higher CAT score groups (Table 2). Overall, treatment with maintenance bronchodilator monotherapy (long-acting muscarinic antagonist [LAMA] or long-acting $\beta_{2}$-agonist [LABA]) was currently prescribed to $18.3 \%$ of patients, with regional variations between single LAMA or LABA use (Table 2). In Europe and the USA, where LAMAs alone were prescribed much more widely than in China, it was more common for only a LAMA to be prescribed to patients with CAT scores of 0-9 or 10-19 than to those with CAT scores of 20-29 and 30-40 (Table 2).

Regional differences were also found between prescription of maintenance bronchodilator dual therapy (LABA and LAMA; Table 2). In Europe, where use of this treatment was more common than in the other regions, prescribing was similar in each of the CAT score groups (Table 2).

Inhaled corticosteroid (ICS)/LABA dual therapy was prescribed for a quarter of patients in the USA and China cohorts and $15.7 \%$ of the Europe cohort, and was the most prescribed treatment in the China cohort (Table 2). In the USA cohort, similar proportions of patients in each CAT score cohort received ICS/LABA, whereas in China, half of the patients in the CAT 0-9 cohort were using ICS/LABA, although the sample size was small ( $n=9$; Table 2$)$. Higher proportions of maintenance triple combination therapy (ICS plus LAMA and LABA) were found in the USA and Europe cohorts (where this was the most prescribed treatment approach) compared with the China cohort. Trends in triple combination prescription by CAT score were different between regions, with similar proportions of prescriptions in all groups in the USA and increasing prescriptions in higher
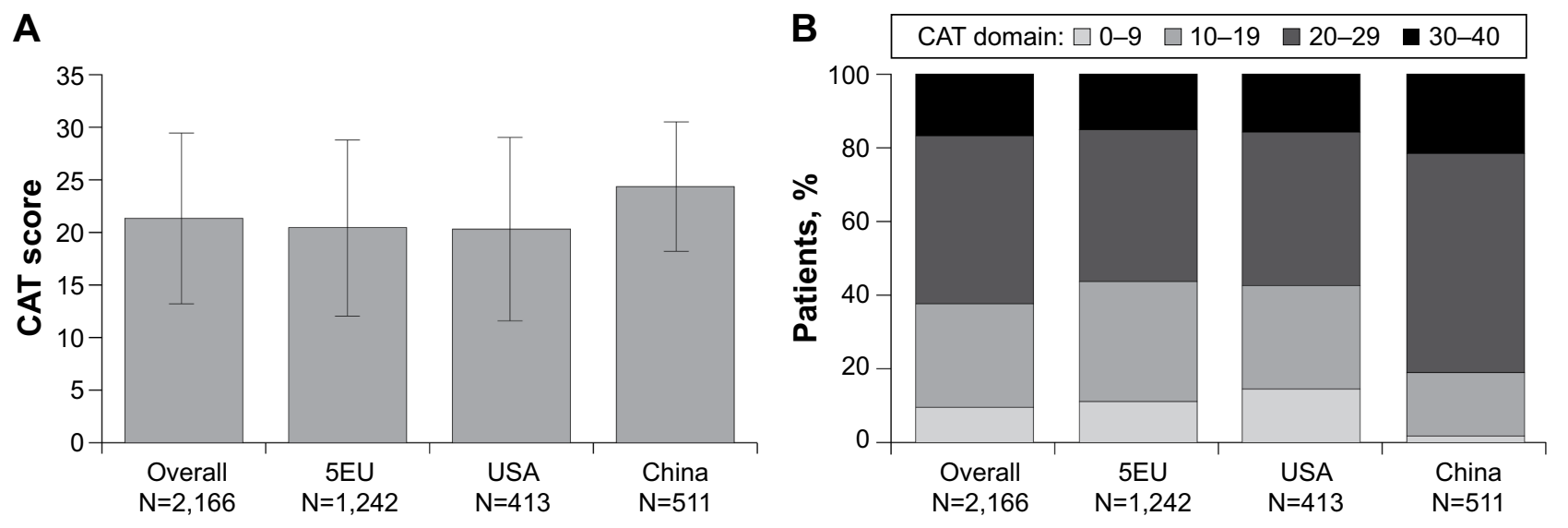

Figure I (A) CAT scores (mean, SD) and (B) CAT score domains by region, \% patients.

Abbreviations: 5EU, France, Germany, Italy, Spain and the UK; CAT, COPD Assessment Test; COPD, chronic obstructive pulmonary disease; SD, standard deviation. 
Table 2 Current treatment ( $\geq 1.5 \%$ of the entire study population) by CAT score domain in all and individual regions

\begin{tabular}{|c|c|c|c|c|c|c|c|c|c|c|}
\hline & \multicolumn{5}{|c|}{ Entire study population } & \multicolumn{5}{|l|}{ 5EU } \\
\hline & Overall & $0-9$ & $10-19$ & $20-29$ & $30-40$ & Overall & $0-9$ & $10-19$ & $20-29$ & $30-40$ \\
\hline & $\begin{array}{l}(N=2,166, \\
100 \%)\end{array}$ & $\begin{array}{l}(n=207 \\
9.6 \%)\end{array}$ & $\begin{array}{l}(n=609, \\
28.1 \%)\end{array}$ & $\begin{array}{l}(n=988 \\
45.6 \%)\end{array}$ & $\begin{array}{l}(n=362 \\
16.7 \%)\end{array}$ & $\begin{array}{l}(N=I, 242, \\
100 \%)\end{array}$ & $\begin{array}{l}(n=138 \\
11.1 \%)\end{array}$ & $\begin{array}{l}(n=405, \\
32.6 \%)\end{array}$ & $\begin{array}{l}(n=5 \mid 2, \\
41.2 \%)\end{array}$ & $\begin{array}{l}(n=187, \\
15.1 \%)\end{array}$ \\
\hline \multicolumn{11}{|l|}{ Current treatment, $\mathrm{n}(\%)$} \\
\hline Missing, $\mathrm{n}$ & 6 & 2 & I & 2 & I & 2 & 1 & 0 & I & 0 \\
\hline \multicolumn{11}{|l|}{ Short-acting therapy } \\
\hline \multicolumn{11}{|l|}{ SABA/SAMA alone ${ }^{a}$} \\
\hline \multicolumn{11}{|l|}{ Maintenance therapies } \\
\hline \multicolumn{11}{|c|}{ Bronchodilator monotherapy } \\
\hline LAMA alone & $313(14.5)$ & $59(28.8)$ & $|4|(23.2)$ & $96(9.7)$ & 17 (4.7) & $236(19.0)$ & $45(32.9)$ & II 2 (27.7) & $69(\mid 3.5)$ & $10(5.4)$ \\
\hline LABA alone & $83(3.8)$ & $16(7.8)$ & $27(4.4)$ & $33(3.4)$ & $7(1.9)$ & $73(5.9)$ & $16(11.7)$ & $26(6.4)$ & $25(4.9)$ & $6(3.2)$ \\
\hline \multicolumn{11}{|c|}{ Bronchodilator dual therapy } \\
\hline LAMA+LABA & $129(6.0)$ & $16(7.8)$ & $39(6.4)$ & $58(5.9)$ & $16(4.4)$ & $123(9.9)$ & $15(11.0)$ & $38(9.4)$ & $55(10.8)$ & $15(8.0)$ \\
\hline \multicolumn{11}{|l|}{ Triple therapy ${ }^{\mathrm{b}}$} \\
\hline LAMA+ICS/LABA & $525(24.3)$ & $31(15.1)$ & $130(2 \mid .4)$ & $243(24.7)$ & I2I (33.5) & $385(31.1)$ & $18(13.1)$ & $92(22.7)$ & I8I (35.4) & $94(50.3)$ \\
\hline$L A M A+L A B A+I C S$ & $32(1.5)$ & $2(1.0)$ & II (I.8) & $12(1.2)$ & $7(1.9)$ & $27(2.2)$ & $2(1.5)$ & $9(2.2)$ & II (2.2) & $5(2.7)$ \\
\hline \multicolumn{11}{|c|}{ ICS-based therapies not including dual LAMA+LABA component } \\
\hline ICS alone & $39(1.8)$ & $4(2.0)$ & $12(2.0)$ & $14(1.4)$ & $9(2.5)$ & $21(1.7)$ & $2(1.5)$ & $9(2.2)$ & $8(1.6)$ & $2(1.1)$ \\
\hline ICS/LABA alone & $432(20.0)$ & $35(17.1)$ & $109(17.9)$ & $214(2 \mid .7)$ & $74(20.5)$ & $194(15.7)$ & $15(11.0)$ & $67(16.5)$ & $86(16.8)$ & $26(13.9)$ \\
\hline ICS+LAMA & $27(\mathrm{I} .3)$ & $2(1.0)$ & $9(1.5)$ & $8(0.8)$ & $8(2.2)$ & $17(1.4)$ & I (0.7) & $6(1.5)$ & $4(0.8)$ & $6(3.2)$ \\
\hline ICS+LABA & $20(0.9)$ & I (0.5) & $2(0.3)$ & $8(0.8)$ & $9(2.5)$ & $10(0.8)$ & I (0.7) & $2(0.5)$ & $3(0.6)$ & $4(2.1)$ \\
\hline ICS/LABA+LTRA & $58(2.7)$ & 0 & $17(2.8)$ & $32(3.3)$ & $9(2.5)$ & $3(0.2)$ & 0 & $\mathrm{I}(0.3)$ & $2(0.4)$ & 0 \\
\hline ICS/LABA+xanthines & $112(5.2)$ & $2(1.0)$ & II (I.8) & $76(7.7)$ & $23(6.4)$ & $9(0.7)$ & I (0.7) & $\mathrm{I}(0.3)$ & $6(1.2)$ & $\mathrm{I}(0.5)$ \\
\hline ICS+xanthines & $30(I .4)$ & 0 & $5(0.8)$ & $22(2.2)$ & $3(0.8)$ & $\mathrm{I}(0.1)$ & 0 & $\mathrm{I}(0.3)$ & 0 & 0 \\
\hline \multicolumn{11}{|c|}{ Other maintenance therapies } \\
\hline Xanthines alone & $61(2.8)$ & 0 & $16(2.6)$ & $34(3.5)$ & II (3.I) & $4(0.3)$ & 0 & 0 & $4(0.8)$ & 0 \\
\hline \multirow[t]{4}{*}{ Other } & I7I (7.9) & $4(2.0)$ & $44(7.2)$ & $86(8.7)$ & $37(10.2)$ & $69(5.6)$ & $2(1.5)$ & $20(4.9)$ & $34(6.7)$ & $13(7.0)$ \\
\hline & \multicolumn{5}{|l|}{ USA } & \multicolumn{5}{|l|}{ China } \\
\hline & Overall & $0-9$ & $10-19$ & $20-29$ & $30-40$ & Overall & $0-9$ & $10-19$ & $20-29$ & $30-40$ \\
\hline & $\begin{array}{l}(\mathrm{N}=4 \mid 3 \\
100 \%)\end{array}$ & $\begin{array}{l}(n=60, \\
14.5 \%)\end{array}$ & $\begin{array}{l}(n=116, \\
28.1 \%)\end{array}$ & $\begin{array}{l}(n=172 \\
41.6 \%)\end{array}$ & $\begin{array}{l}(n=65 \\
\mid 5.7 \%)\end{array}$ & $\begin{array}{l}(N=5 \mathrm{I}, \\
100 \%)\end{array}$ & $\begin{array}{l}(n=9, \\
1.8 \%)\end{array}$ & $\begin{array}{l}(n=88, \\
17.2 \%)\end{array}$ & $\begin{array}{l}(n=304, \\
59.5 \%)\end{array}$ & $\begin{array}{l}(n=I 10, \\
21.5 \%)\end{array}$ \\
\hline \multicolumn{11}{|l|}{ Current treatment, n (\%) } \\
\hline Missing, $\mathrm{n}$ & 3 & I & I & I & 0 & I & 0 & 0 & 0 & I \\
\hline \multicolumn{11}{|l|}{ Short-acting therapy } \\
\hline $\begin{array}{l}\text { SABA, SAMA, } \\
\text { SABA/SAMA alone }{ }^{\mathrm{a}}\end{array}$ & $4 \mid(10.0)$ & $13(22.0)$ & $9(7.8)$ & $18(10.5)$ & I (I.5) & $19(3.7)$ & I (II.I) & $5(5.7)$ & $9(3.0)$ & $4(3.7)$ \\
\hline Maintenance therapies & & & & & & & & & & \\
\hline Bronchodilator mono & erapy & & & & & & & & & \\
\hline LAMA alone & $73(17.8)$ & $14(23.7)$ & $29(25.2)$ & $24(14.0)$ & $6(9.2)$ & $4(0.8)$ & 0 & 0 & $3(1.0)$ & $\mathrm{I}(0.9)$ \\
\hline LABA alone & $5(1.2)$ & 0 & I (0.9) & $4(2.3)$ & 0 & $5(1.0)$ & 0 & 0 & $4(1.3)$ & I (0.9) \\
\hline Bronchodilator dual the & rapy & & & & & & & & & \\
\hline LAMA+LABA & $5(1.2)$ & I (I.7) & I (0.9) & $2(1.2)$ & $\mathrm{I}(\mathrm{I} .5)$ & $\mathrm{I}(0.2)$ & 0 & 0 & $\mathrm{I}(0.3)$ & 0 \\
\hline Triple therapy ${ }^{\mathrm{b}}$ & & & & & & & & & & \\
\hline LAMA+ICS/LABA & $132(32.2)$ & $13(22.0)$ & $37(32.2)$ & $60(35.1)$ & $22(33.9)$ & $8(1.6)$ & 0 & $\mathrm{I}(\mathrm{I} . \mathrm{I})$ & $2(0.7)$ & $5(4.6)$ \\
\hline LAMA+LABA+ICS & $5(1.2)$ & 0 & $2(1.7)$ & $\mathrm{I}(0.6)$ & $2(3.1)$ & 0 & 0 & 0 & 0 & 0 \\
\hline ICS-based therapies no & including dua & I LAMA+LA & ABA comp & ent & & & & & & \\
\hline ICS alone & $7(1.7)$ & I (I.7) & $\mathrm{I}(0.9)$ & $2(1.2)$ & $3(4.6)$ & II (2.2) & I (II.I) & $2(2.3)$ & $4(1.3)$ & $4(3.7)$ \\
\hline ICS/LABA alone & $106(25.9)$ & $15(25.4)$ & $27(23.5)$ & $45(26.3)$ & $19(29.2)$ & $132(25.9)$ & $5(55.6)$ & $15(17.0)$ & $83(27.3)$ & $29(26.6)$ \\
\hline ICS+LAMA & $10(2.4)$ & I (I.7) & $3(2.6)$ & $4(2.3)$ & $2(3.1)$ & 0 & 0 & 0 & 0 & 0 \\
\hline ICS+LABA & $6(1.5)$ & 0 & 0 & $4(2.3)$ & $2(3.1)$ & $4(0.8)$ & 0 & 0 & I (0.3) & $3(2.8)$ \\
\hline ICS/LABA+LTRA & $\mathrm{I}(0.2)$ & 0 & I (0.9) & 0 & 0 & $54(10.6)$ & 0 & $15(17.1)$ & $30(9.9)$ & $9(8.3)$ \\
\hline ICS/LABA+xanthines & 0 & 0 & 0 & 0 & 0 & $103(20.2)$ & I (II.I) & $10(11.4)$ & $70(23.0)$ & $22(20.2)$ \\
\hline ICS+xanthines & I $(0.2)$ & 0 & 0 & I (0.6) & 0 & $28(5.5)$ & 0 & $4(4.6)$ & $21(6.9)$ & $3(2.8)$ \\
\hline Other maintenance ther & apies & & & & & & & & & \\
\hline Xanthines alone & 0 & 0 & 0 & 0 & 0 & $57(11.2)$ & 0 & $16(18.2)$ & $30(9.9)$ & II (10.I) \\
\hline Other & $18(4.4)$ & I (I.7) & $4(3.5)$ & $6(3.5)$ & $7(10.8)$ & $84(16.5)$ & I (II.I) & $20(22.7)$ & $46(15.1)$ & $17(15.6)$ \\
\hline
\end{tabular}

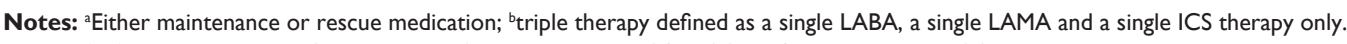

Abbreviations: 5EU, France, Germany, Italy, Spain and the UK; CAT, COPD Assessment Test; COPD, chronic obstructive pulmonary disease; ICS, inhaled corticosteroid; LABA, long-acting $\beta_{2}$-agonist; LAMA, long-acting muscarinic antagonist; LTRA, leukotriene receptor antagonist; SABA, short-acting $\beta_{2}$-agonist; SAMA, short-acting muscarinic antagonist. 
groups in Europe and China (Table 2). In contrast to Europe and the USA where xanthines are not used, xanthines (used as part of a combination therapy) represented the second and fourth highest treatment strategy in China (Table 2; Tables S2-S4).

\section{HCRU by CAT score}

Over the 12 months prior to the study period, surveyed patients reported an average (SD) of 6.6 (5.5) visits to their physician for their COPD. Primary care physician visits were the most frequent (mean [SD]: 4.5 [4.8]), with pulmonologist visits and ED treatment/hospitalizations for exacerbations occurring a mean (SD) of 1.7 (1.9) and 0.4 (1.3) times, respectively (Table 3 ). Multivariate negative binomial regression modeling of HCRU by CAT score revealed a significant association between increased visits to a physician and increasing CAT score. For each unit increase in CAT score, the rate of visits to any physician in the last 12 months increased by a factor of $1.024(2.4 \% ; P<0.001$; Table 4$)$. Within this analysis, the number of primary care physician visits was significantly greater with increasing CAT score (incident rate ratio [IRR]: $1.029 ; P<0.001)$, as were pulmonologist visits (IRR: $1.012 ; P=0.007)$. In the past 12 months, the number of exacerbations requiring ED treatment or hospitalization (unscheduled hospital visits) was significantly greater with increasing CAT score (IRR: $1.112 ; P<0.001$ ).

\section{WPAI by CAT score}

Overall work impairment (absenteeism and presenteeism combined), as quantified by mean WPAI score, was $24.9 \pm 21.6$ (mean [SD]; Table 3). Over the 7 days prior to the study period, a significant association was observed between increasing absenteeism from work and increasing CAT score (coefficient: $0.445 ; P=0.002$; Table 4). For each unit increase in CAT score, there was an increase in absenteeism of $0.45 \%$ points. Thus, an increase in CAT score of 10 is associated with an increase in absenteeism of $4.5 \%$ points. Over the same time period, a higher CAT score was associated with impaired work time (presenteeism; coefficient: 1.680; $P<0.001$; Table 4). Thus, for each unit increase in CAT score, there was an increase in presenteeism of $1.68 \%$ points. Likewise, loss of work productivity (overall work impairment) was significantly associated with increasing CAT score (coefficient: 1.739; $P<0.001$; Table 4). Total activity impairment was also significantly associated with increasing CAT score (coefficient: 2.004; $P<0.001$; Table 4),

Table 3 The burden of COPD in relation to HCRU and WPAI in all and individual regions, and overall by CAT score domain

\begin{tabular}{|c|c|c|c|c|c|c|c|c|}
\hline & \multicolumn{8}{|c|}{ Individual regions } \\
\hline & \multicolumn{2}{|c|}{ Overall } & \multicolumn{2}{|l|}{ 5EU } & \multicolumn{2}{|c|}{ USA } & \multicolumn{2}{|c|}{ China } \\
\hline & $\mathbf{n}$ & Mean (SD) & $\mathbf{n}$ & Mean (SD) & $\mathbf{n}$ & Mean (SD) & $\mathbf{n}$ & Mean (SD) \\
\hline Total physician visits in the last 12 months & $\mathrm{I}, 560$ & $6.6(5.5)$ & $\mathrm{I}, 053$ & $6.5(4.9)$ & 319 & $4.2(2.9)$ & 188 & $10.8(8.6)$ \\
\hline Primary care physician visits in the last 12 months & $\mathrm{I}, 734$ & $4.5(4.8)$ & 1,055 & $3.6(3.4)$ & 321 & $2.0(1.7)$ & 358 & $9.2(6.5)$ \\
\hline Pulmonologist visits in the last 12 months & $\mathrm{I}, 587$ & $\mathrm{I} .7(\mathrm{I} .8)$ & 1,059 & $1.8(1.7)$ & 338 & $1.9(2.2)$ & 190 & $0.6(1.5)$ \\
\hline Unscheduled hospital visits in the last 12 months & 1,664 & $0.4(1.3)$ & 1,056 & $0.3(0.8)$ & 333 & $0.3(0.8)$ & 275 & $0.8(2.6)$ \\
\hline Work time missed (absenteeism) in the last 7 days, $\%$ & 290 & $4.9(17.4)$ & 206 & $5.7(18.7)$ & 84 & $17.8(20.4)$ & $\mathrm{n} / \mathrm{a}$ & $\mathrm{n} / \mathrm{a}$ \\
\hline Work time impaired (presenteeism) in the last 7 days, $\%$ & 282 & $23.5(20.1)$ & 200 & $25.9(19.6)$ & 82 & $17.8(20.4)$ & $\mathrm{n} / \mathrm{a}$ & $\mathrm{n} / \mathrm{a}$ \\
\hline $\begin{array}{l}\text { Overall work impairment (combination of absenteeism } \\
\text { and presenteeism) in the last } 7 \text { days, } \%\end{array}$ & 281 & $24.9(21.6)$ & 199 & $27.4(21.1)$ & 82 & $18.9(2 \mid .7)$ & $\mathrm{n} / \mathrm{a}$ & $\mathrm{n} / \mathrm{a}$ \\
\hline \multirow[t]{4}{*}{ Total activity impairment in the last 7 days, $\%$} & 1,066 & $39.9(25.2)$ & 836 & $41.4(24.7)$ & 230 & $34.6(26.1)$ & $\mathrm{n} / \mathrm{a}$ & $\mathrm{n} / \mathrm{a}$ \\
\hline & \multicolumn{8}{|c|}{ Overall by CAT score domain } \\
\hline & \multicolumn{2}{|l|}{$0-9$} & \multicolumn{2}{|l|}{$10-19$} & \multicolumn{2}{|c|}{$20-29$} & \multicolumn{2}{|c|}{$30-40$} \\
\hline & $\mathbf{n}$ & Mean (SD) & $\mathbf{n}$ & Mean (SD) & $\mathbf{n}$ & Mean (SD) & $\mathbf{n}$ & Mean (SD) \\
\hline Total physician visits in the last 12 months & 159 & $4.4(3.5)$ & 464 & $5.6(4.3)$ & 666 & $6.9(5.7)$ & 271 & $8.7(6.7)$ \\
\hline Primary care physician visits in the last 12 months & 161 & $2.6(2.6)$ & 481 & $3.5(3.6)$ & 792 & $5.0(5.2)$ & 300 & $5.5(5.5)$ \\
\hline Pulmonologist visits in the last 12 months & 167 & $\mathrm{I} .4(\mathrm{I} .5)$ & 471 & $1.5(1.7)$ & 675 & $1.7(2.0)$ & 274 & $2.0(2.0)$ \\
\hline Unscheduled hospital visits in the last 12 months & 164 & $0.1(0.3)$ & 478 & $0.1(0.5)$ & 757 & $0.4(1.3)$ & 265 & I.I (2.2) \\
\hline Work time missed (absenteeism) in the last 7 days, $\%$ & 55 & $0.1(I . I)$ & 125 & $3.3(13.9)$ & 91 & $9.4(23.4)$ & 19 & $8.4(24.3)$ \\
\hline Work time impaired (presenteeism) in the last 7 days, $\%$ & 55 & $6.9(9.2)$ & 122 & $19.5(15.7)$ & 87 & $33.8(18.8)$ & 18 & $51.7(21.8)$ \\
\hline $\begin{array}{l}\text { Overall work impairment (combination of absenteeism } \\
\text { and presenteeism) in the last } 7 \text { days, \% }\end{array}$ & 55 & $7.1(9.2)$ & 122 & $20.7(16.8)$ & 86 & $36.5(21.1)$ & 18 & $52.7(22.6)$ \\
\hline Total activity impairment in the last 7 days, $\%$ & 130 & $12.8(14.5)$ & 347 & $28.5(18.7)$ & 444 & $47.2(20.2)$ & 145 & $69.4(19.3)$ \\
\hline
\end{tabular}

Abbreviations: 5EU, France, Germany, Italy, Spain and the UK; CAT, COPD Assessment Test; COPD, chronic obstructive pulmonary disease; HCRU, health care resource utilization; n/a, not available; SD, standard deviation; WPAI, work productivity and activity impairment. 
Table 4 Incremental burden of COPD associated with increasing CAT score in relation to HCRU, work productivity and activity impairment

\begin{tabular}{|c|c|c|c|c|c|c|}
\hline \multirow[b]{3}{*}{ Total physician visits in the last 12 months } & \multirow{3}{*}{$\begin{array}{l}\mathbf{n} \\
\mathrm{I}, 560\end{array}$} & \multirow{3}{*}{$\begin{array}{l}\text { Mean (SD) } \\
6.6(5.5)\end{array}$} & \multicolumn{4}{|c|}{ Multivariate regression modeling } \\
\hline & & & \multirow{2}{*}{$\begin{array}{l}\text { IRR/coefficient } \\
\text { I.024 }\end{array}$} & \multicolumn{2}{|l|}{$95 \% \mathrm{Cl}$} & \multirow{2}{*}{$\frac{P \text {-value }}{<0.001}$} \\
\hline & & & & 1.018 & 1.030 & \\
\hline Primary care physician visits in the last 12 months & $\mathrm{I}, 734$ & $4.5(4.8)$ & $1.029^{\mathrm{a}}$ & 1.021 & 1.038 & $<0.001$ \\
\hline Pulmonologist visits in the last 12 months & I,587 & $1.7(1.9)$ & $1.012^{\mathrm{a}}$ & 1.003 & 1.020 & 0.007 \\
\hline Unscheduled hospital visits in the last 12 months & 1,664 & $0.4(1.3)$ & $1.112^{\mathrm{a}}$ & 1.089 & 1.137 & $<0.00$ I \\
\hline Work time missed (absenteeism) in the last 7 days, $\%$ & 290 & $4.9(17.4)$ & $0.445^{b}$ & 0.169 & 0.720 & 0.002 \\
\hline Work time impaired (presenteeism) in the last 7 days, $\%$ & 282 & $23.5(20.1)$ & $1.680^{\mathrm{b}}$ & 1.392 & 1.967 & $<0.001$ \\
\hline $\begin{array}{l}\text { Overall work impairment (combination of absenteeism } \\
\text { and presenteeism) in the last } 7 \text { days, } \%\end{array}$ & 281 & $24.9(21.6)$ & $1.739^{b}$ & 1.429 & 2.048 & $<0.001$ \\
\hline Total activity impairment in the last 7 days, $\%$ & 1,066 & $39.9(25.2)$ & $2.004^{b}$ & 1.848 & 2.160 & $<0.001$ \\
\hline
\end{tabular}

Notes: alRR; 'bcoefficient.

Abbreviations: CAT, COPD Assessment Test; $\mathrm{Cl}$, confidence interval; COPD, chronic obstructive pulmonary disease; HCRU, health care resource utilization; IRR, incidence rate ratio; SD, standard deviation.

so that for each unit increase in CAT score, there was an increase in activity impairment of $2 \%$ points.

\section{Discussion}

In this study, the majority of patients with COPD ( $>90 \%$ of the total population) presented with a high symptom burden, based on the established threshold value of $\geq 10$ on the CAT. ${ }^{5,9}$ The mean CAT score in our study was 21.3 (median 22; $62.3 \%$ had a CAT score $\geq 20$ ). This trend was particularly pronounced in China, with almost all of the patients surveyed presenting with a high symptom burden, and may reflect the country's health care system, where patient consultations typically occur in hospitals and are more suggestive of emergency care than routine visits. The CAT cut-point for regular treatment based on symptoms is a score $\geq 10$, which may be too low to accurately distinguish patients based on the presence of a clinically meaningful symptom burden. ${ }^{5}$ The cut-point does correspond to the range of severity typically observed in patients recruited to clinical trials in COPD. ${ }^{5}$ The distribution of CAT scores observed herein serves to underline the differences between clinical trial populations and the patient populations that physicians may encounter in routine clinical practice. Our decision to assess CAT scores as a continuous variable from 0 to 40 was intended to capture more accurate information on the impact on HCRU and work/ activity impairment of progressively worse symptoms, and the apparent skewing of our data toward the upper end of the scale justifies such an approach.

Allowing for differences in the study populations, our findings are broadly consistent with those from a cohort of the COPDGene ${ }^{\circledR}$ study, which found that more patients were grouped within "high symptom" groups (GOLD-B, 24.8\%; GOLD-D, 41.0\%) than "low symptom" groups (GOLD-A,
29.4\%; GOLD-C, 4.9\%). ${ }^{10}$ Published data have shown that choice of symptom measure can alter the group assignment of patients with COPD. ${ }^{11}$ Indeed, a subsequent systematic review and meta-analysis of 17 studies in patients with COPD confirmed that CAT $\geq 10$ and modified Medical Research Council (mMRC) $\geq 2$ are nonequivalent criteria for assessing symptom burden. ${ }^{12}$ It has been proposed that a lower mMRC-based threshold of grade $\geq 1$ is equivalent to a CAT score $\geq 10$ cut-off when seeking to identify patients with low-symptom COPD. ${ }^{13}$

Further evidence for the high symptom burden among patients with COPD comes from a global study ${ }^{14}$ reporting that while the majority of patients (62\%) were allocated to lower symptom groups (mMRC 1 and 2), the rates of exacerbation requiring hospitalization in the 12 months prior to assessment ( $27 \%$ in mMRC groups 1 and 2) exceed those reported in our study (19.6\%), in which the burden of symptoms was notably higher. While we acknowledge that such differences may derive, in part, from reliance on patient-defined criteria for an exacerbation, rather than physician-defined criteria for an exacerbation, this observation does suggest that a high impact of symptoms on day-to-day life is not necessarily indicative of more serious exacerbation-related events.

The study highlighted the disparity in treatment approaches between Europe, the USA and China, although an exception was the large proportion of patients in each region receiving monotherapy or short-acting therapy only, which may not be adequate to provide optimal symptom control. Triple combination therapy of ICS, LABA and LAMA appeared more widely adopted in the USA and Europe than in China. This is despite being widely acknowledged as the current gold standard optimal inhaled therapy for patients with COPD with more symptoms and high risk of exacerbation 
(D classification). ${ }^{5}$ In line with these findings, a recent retrospective database review from Taiwan showed excessive use of oral bronchodilators (predominantly xanthines and $\beta_{2}$-agonists) in China. ${ }^{15}$ Although not a specific objective of the study, our data suggest a disconnection between physicians' prescribing practices and COPD treatment guidelines. The reasons for this disparity cannot be established from our data set, although in China, one barrier to effective provision of GOLD-recommended treatments has been identified as the self-administration of nonprescription medicines by individuals with COPD. ${ }^{16}$

A particular focus of this study was translating the impact of increments in activity impairment on HCRU and work productivity. Jones et al reported that a CAT score of 5 may prevent patients from performing one or two tasks and a score of 10 means that patients get exhausted easily and usually cannot play sports, whereas a score $>30$ prevents them from doing most of what they want to do. ${ }^{9}$

In our survey, increasing severity of COPD symptoms was directly and significantly associated with HCRU. For each unit increase in CAT score, the rate of unscheduled visits to hospital related to an exacerbation increased by $11.2 \%$. Although establishing a causal relationship between the CAT score and serious exacerbation risk was beyond the scope of the study, this association may serve as a useful marker of exacerbation risk in patients newly diagnosed in a primary care setting and in those perceived to be at low risk of exacerbation.

A noteworthy observation was that while a statistically significant difference was seen in physician visits, the absolute increase in visits to either a primary care physician or a pulmonologist was small. One possible explanation is that patients were self-restrained by their symptoms, given their diagnosis of COPD, and were therefore less inclined to seek medical attention. This sense of low expectation was also observed in the study by Barnes et al, in which many patients (39\%) adopted a "wait and see" approach to an exacerbation before seeking medical help. ${ }^{14}$

One quarter of the patients in our survey were actively employed and, therefore, their ability to manage their activity impairment in order to continue working is an important factor not only for financial reasons but also for maintaining a feeling of well-being, self-worth and a sense of contributing to society. Previous studies, conducted in US patient populations, have shown a link between HCRU and/or WPAI and the frequency of exacerbations. ${ }^{6,17,18}$ Our study focused on symptom severity rather than exacerbations and showed that increasing CAT scores were significantly associated with a loss of productivity related to absenteeism (missed days of work) and presenteeism (attending work while sick). In addition, if a minimally important difference is taken to be $\sim 7 \%$, as suggested by research conducted in patients with Crohn's disease, ${ }^{19}$ then this is achieved with only a difference of $\sim 4$ on the CAT score for both overall WPAI score and activity impairment.

The risk of patient selection bias was a noted limitation of the study design; however, the likelihood was limited by the prospective consecutive sampling approach adopted. This approach was contingent upon the integrity of the participating physician, and adherence to this instruction could not be verified. Furthermore, as patients were enrolled from both a primary care and a specialist setting, this could potentially limit the generalizability of the findings. Further research would be necessary to investigate the differences in outcomes between the specialties of the managing physicians. WPAI data were not collected in China but were assessed in the European Union and the USA, which together comprised the majority of patients $(>75 \%)$. Another potential limitation is the point-in-time nature of the CAT, in which patients are asked for the "current" impact of their COPD, whereas independent variables are reported over the last 12 months or 7 days. However, this may have reduced the likelihood of finding an association between symptoms at the present day and events over the preceding 12 months. As an outcome measure, the CAT score was considered to provide a comprehensive assessment of a patient's symptom severity over the previous 12 months. This is consistent with the GOLD classification, whereby patients are assigned to a group based on their current CAT score; however, exacerbation risk is determined on the basis of the last 12 months. Given the nonspecific time period of the items of the CAT and the outpatient setting (only $4.6 \%$ of patients were consulting the physician for a reason related to an exacerbation), their CAT score can be considered representative of symptoms that extend further than just the current day. This further validates conclusions drawn from the correlation observed between more symptoms and higher HCRU, such as serious exacerbation events. Adjusting for confounding demographic variations, smoking history and selected comorbidities helped to further strengthen the significance of the specific association of inadequate symptom control with higher HCRU and impact on work.

\section{Conclusion}

Our study provides important data that support an association between COPD symptom burden and direct/indirect HCRU, 
including physician visits and WPAI. The majority of patients with COPD presented with a high level of symptoms according to their CAT score. A substantial proportion of these patients were receiving single short-acting or maintenance bronchodilator monotherapy, which may be indicative of an undertreated symptom burden that warrants an escalated pharmacotherapeutic intervention. Increasing symptom burden was associated with increasing HCRU and an overall detrimental impact on work productivity.

\section{Acknowledgments}

This study was supported by AstraZeneca. The authors thank Caroline Shepherd, BPharm of Complete Medical Communications, Macclesfield, UK for providing medical writing support, which was funded by AstraZeneca, Cambridge, UK in accordance with Good Publication Practice (GPP3) guidelines (Ann Intern Med 2015;163:461-464).

The authors thank Robert Wood for the analytical support and review of statistical interpretation received for this study.

\section{Author contributions}

All authors contributed toward data analysis, drafting and critically revising the paper, approved the final version to be published and agree to be accountable for all aspects of the work.

\section{Disclosure}

$\mathrm{UH}, \mathrm{GB}$ and $\mathrm{BD}$ are employees of AstraZeneca. MS is an employee of Adelphi Real World. The authors report no other conflicts of interest in this work.

\section{References}

1. World Health Organization. World Health Statistics; 2008 [updated 2008]. Available from: http://www.who.int/whosis/whostat/EN_WHS08_Full. pdf. Accessed on October 30, 2016

2. Wheaton AG, Cunningham TJ, Ford ES, Croft JB. Employment and activity limitations among adults with chronic obstructive pulmonary diseaseUnited States, 2013. MMWR Morb Mortal Wkly Rep. 2015;64(11): 289-295.

3. Waschki B, Kirsten A, Holz O, et al. Physical activity is the strongest predictor of all-cause mortality in patients with COPD: a prospective cohort study. Chest. 2011;140(2):331-342.

4. O'Donnell DE. Impacting patient-centred outcomes in COPD: breathlessness and exercise tolerance. Eur Resp Rev. 2006;15(99):37-41.
5. Global Initiative for Chronic Obstructive Lung Disease. Global Strategy for the Diagnosis, Management and Prevention of COPD, Global Initiative for Chronic Obstructive Lung Disease (GOLD); 2016. Available from: http://www.goldcopd.org/. 2016. Accessed on October 30, 2016.

6. AbuDagga A, Sun SX, Tan H, Solem CT. Healthcare utilization and costs among chronic bronchitis patients treated with maintenance medications from a US managed care population. J Med Econ. 2013; $16(3): 421-429$.

7. Anderson P, Benford M, Harris N, Karavali M, Piercy J. Real-world physician and patient behaviour across countries: disease-specific programmes - a means to understand. Curr Med Res Opin. 2008; 24(11):3063-3072.

8. Reilly MC, Zbrozek AS, Dukes EM. The validity and reproducibility of a work productivity and activity impairment instrument. Pharmacoeconomics. 1993;4(5):353-365.

9. Jones PW, Tabberer M, Chen WH. Creating scenarios of the impact of COPD and their relationship to COPD Assessment Test (CAT $\left.{ }^{\mathrm{TM}}\right)$ scores. BMC Pulm Med. 2011;11:42.

10. Han MK, Muellerova H, Curran-Everett D, et al. GOLD 2011 disease severity classification in COPDGene: a prospective cohort study. Lancet Respir Med. 2013;1(1):43-50.

11. Price DB, Baker CL, Zou KH, Higgins VS, Bailey JT, Pike JS. Realworld characterization and differentiation of the Global Initiative for Chronic Obstructive Lung Disease strategy classification. Int J Chron Obstruct Pulmon Dis. 2014;9:551-561.

12. Karloh M, Fleig MA, Maurici R, Pizzichini MM, Jones PW, Pizzichini E. The COPD Assessment Test: what do we know so far?: a systematic review and meta-analysis about clinical outcomes prediction and classification of patients into GOLD stages. Chest. 2016;149(2):413-425.

13. Jones PW, Adamek L, Nadeau G, Banik N. Comparisons of health status scores with MRC grades in COPD: implications for the GOLD 2011 classification. Eur Respir J. 2013;42(3):647-654.

14. Barnes N, Calverley PM, Kaplan A, Rabe KF. Chronic obstructive pulmonary disease and exacerbations: patient insights from the global Hidden Depths of COPD survey. BMC Pulm Med. 2013;13:54.

15. Dong YH, Hsu CL, Li YY, Chang CH, Lai MS. Bronchodilators use in patients with COPD. Int $J$ Chron Obstruct Pulmon Dis. 2015;10: 1769-1779.

16. Cao G, Li J, Li L, et al. Use of nonprescription medicines by patients with COPD: a survey in Chongqing Municipality, China. Chron Respir Dis. 2012;9(2):77-81.

17. Pasquale MK, Sun SX, Song F, Hartnett HJ, Stemkowski SA. Impact of exacerbations on health care cost and resource utilization in chronic obstructive pulmonary disease patients with chronic bronchitis from a predominantly Medicare population. Int J Chron Obstruct Pulmon Dis. 2012;7:757-764.

18. Solem CT, Sun SX, Sudharshan L, Macahilig C, Katyal M, Gao X. Exacerbation-related impairment of quality of life and work productivity in severe and very severe chronic obstructive pulmonary disease. Int $J$ Chron Obstruct Pulmon Dis. 2013;8:641-652.

19. Feagan BG, Sandborn WJ, Wolf DC, et al. Randomised clinical trial: improvement in health outcomes with certolizumab pegol in patients with active Crohn's disease with prior loss of response to infliximab. Aliment Pharmacol Ther. 2011;33(5):541-550. 


\section{Supplementary materials}

Table SI Patient comorbidity profile

\begin{tabular}{|c|c|c|c|c|}
\hline & $\frac{\text { Overall }}{(\mathrm{N}=2,166)}$ & $\frac{5 E U}{(n=I, 242)}$ & $\frac{\text { USA }}{(n=4 \mid 3)}$ & $\frac{\text { China }}{(n=5 I I)}$ \\
\hline \multicolumn{5}{|l|}{ Cardiovascular condition, n (\%) } \\
\hline Missing, $\mathrm{n}$ & 57 & 42 & 10 & 5 \\
\hline Angina pectoris & III (5.3) & $91(7.6)$ & $9(2.2)$ & II (2.2) \\
\hline Cardiac arrhythmias & $165(7.8)$ & $108(9.0)$ & $22(5.5)$ & $35(6.9)$ \\
\hline Coagulated blood clotting disorder & $18(0.9)$ & $10(0.8)$ & $5(1.2)$ & $3(0.6)$ \\
\hline Congestive heart failure & $105(5.0)$ & $59(4.9)$ & $34(8.4)$ & $12(2.4)$ \\
\hline Coronary artery disease & $179(8.5)$ & $70(5.8)$ & $50(12.4)$ & 59 (II.7) \\
\hline Elevated cholesterol/hyperlipidemia & $569(27.0)$ & $328(27.3)$ & $170(42.2)$ & $71(14.0)$ \\
\hline Hypertension & $\mathrm{I}, \mathrm{I} 76(55.8)$ & $728(60.7)$ & $269(66.8)$ & $179(35.4)$ \\
\hline Myocardial infarction & 81 (3.8) & $65(5.4)$ & $8(2.0)$ & $8(1.6)$ \\
\hline Peripheral vascular disease & $106(5.0)$ & $66(5.5)$ & $37(9.2)$ & $3(0.6)$ \\
\hline Pulmonary arterial hypertension & $5 \mathrm{I}(2.4)$ & $24(2.0)$ & $7(1.7)$ & $20(4.0)$ \\
\hline Cerebrovascular disease and/or stroke & $46(2.2)$ & $26(2.2)$ & $10(2.5)$ & $10(2.0)$ \\
\hline Thrombosis & $21(1.0)$ & $10(0.8)$ & $4(1.0)$ & $7(1.4)$ \\
\hline Other CV condition & $32(1.5)$ & $24(2.0)$ & $4(1.0)$ & $4(0.8)$ \\
\hline None & $679(32.2)$ & $346(28.8)$ & $86(21.3)$ & $247(48.8)$ \\
\hline \multicolumn{5}{|l|}{ Physician-confirmed serious CV condition ${ }^{\mathrm{a}}$, n (\%) } \\
\hline Missing, $\mathrm{n}$ & 57 & 42 & 10 & 5 \\
\hline Serious CV & $574(27.2)$ & $334(27.8)$ & II 8 (29.3) & $122(24.1)$ \\
\hline \multicolumn{5}{|l|}{ Other concomitant conditions ${ }^{\mathrm{b}}, \mathrm{n}(\%)$} \\
\hline Missing, $n$ & 196 & 45 & 20 & $|3|$ \\
\hline None & $275(14.0)$ & $253(2 I .1)$ & $22(5.6)$ & 0 \\
\hline AIDS/HIV & $5(0.3)$ & $4(0.3)$ & 0 & $\mathrm{I}(0.3)$ \\
\hline Anemia & $63(3.2)$ & $24(2.0)$ & $14(3.6)$ & $25(6.6)$ \\
\hline Anxiety & $223(11.3)$ & $128(10.7)$ & $70(17.8)$ & $25(6.6)$ \\
\hline Arthritis & $271(13.8)$ & $109(9.1)$ & $110(28.0)$ & $52(13.7)$ \\
\hline Atopic dermatitis & $10(0.5)$ & $5(0.4)$ & $3(0.8)$ & $2(0.5)$ \\
\hline Cancer & $44(2.2)$ & $30(2.5)$ & II (2.8) & $3(0.8)$ \\
\hline Crohn's disease & $12(0.6)$ & $10(0.8)$ & $\mathrm{I}(0.3)$ & $\mathrm{I}(0.3)$ \\
\hline Connective tissue/rheumatologic disease & $12(0.6)$ & $3(0.3)$ & $6(1.5)$ & $3(0.8)$ \\
\hline Dementia & $18(0.9)$ & $10(0.8)$ & $5(1.3)$ & $3(0.8)$ \\
\hline Depression & $184(9.3)$ & $121(10.1)$ & $60(15.3)$ & $3(0.8)$ \\
\hline Dermatitis/eczema & $18(0.9)$ & $6(0.5)$ & $4(1.0)$ & $8(2.1)$ \\
\hline Diabetes & $305(15.5)$ & $208(17.4)$ & $54(13.7)$ & $43(11.3)$ \\
\hline Dyspepsia/stomach pain & $121(6.1)$ & $40(3.3)$ & $13(3.3)$ & $68(17.9)$ \\
\hline Gastroesophageal reflux disease & $217(11.0)$ & $121(10.1)$ & $89(22.7)$ & $7(1.8)$ \\
\hline Glaucoma & $43(2.2)$ & $26(2.2)$ & $10(2.5)$ & $7(1.8)$ \\
\hline Hyperthyroidism & $28(1.4)$ & $21(1.8)$ & $6(1.5)$ & I $(0.3)$ \\
\hline Liver disease & $46(2.3)$ & $33(2.8)$ & $5(1.3)$ & $8(2.1)$ \\
\hline Obesity & $155(7.9)$ & $112(9.4)$ & $32(8.1)$ & II (2.9) \\
\hline Osteoporosis & $167(8.5)$ & $86(7.2)$ & $36(9.2)$ & $45(11.8)$ \\
\hline Prostate disorder & $168(8.5)$ & $122(10.2)$ & $38(9.7)$ & $8(2.1)$ \\
\hline Psoriasis & II $(0.6)$ & $6(0.5)$ & $2(0.5)$ & $3(0.8)$ \\
\hline Peptic ulcer disease & $57(2.9)$ & $15(1.3)$ & $6(1.5)$ & $36(9.5)$ \\
\hline Renal failure & $40(2.0)$ & $31(2.6)$ & $3(0.8)$ & $6(1.6)$ \\
\hline Sinusitis & $58(2.9)$ & II (0.9) & $9(2.3)$ & $38(10.0)$ \\
\hline Sleep apnea & $102(5.2)$ & $59(4.9)$ & $30(7.6)$ & $13(3.4)$ \\
\hline
\end{tabular}

Notes: aSerious $\mathrm{CV}$ is defined as conditions such as angina and congestive heart failure and excludes the $\mathrm{CV}$ risk factors hypertension and hyperlipidemia; ${ }^{\mathrm{b}} \mathrm{concomitant}$ conditions list is not exhaustive. All variables are physician reported, with the exception of employment status.

Abbreviations: 5EU, France, Germany, Italy, Spain and the UK; AIDS, acquired immunodeficiency syndrome; CV, cardiovascular; HIV, human immunodeficiency virus. 
Table S2 Current treatment by CAT score domain in the USA

\begin{tabular}{|c|c|c|c|c|c|}
\hline & Overall $(N=4 \mid 3)$ & $0-9(n=60)$ & $10-19(n=116)$ & $20-29(n=172)$ & $30-40(n=65)$ \\
\hline \multicolumn{6}{|l|}{ Current treatment, $\mathrm{n}(\%)$} \\
\hline Missing, $n$ & 3 & I & I & I & 0 \\
\hline \multicolumn{6}{|l|}{ Short-acting therapy } \\
\hline SABA, SAMA, SABA/SAMA alone & $4 I(10.0)$ & $13(22.0)$ & $9(7.8)$ & $18(10.5)$ & $\mathrm{I}(\mathrm{I} .5)$ \\
\hline \multicolumn{6}{|l|}{ Maintenance therapies } \\
\hline \multicolumn{6}{|l|}{ Bronchodilator monotherapy } \\
\hline LAMA alone & $73(17.8)$ & $14(23.7)$ & $29(25.2)$ & $24(14.0)$ & $6(9.2)$ \\
\hline LABA alone & $5(1.2)$ & 0 & $\mathrm{I}(0.9)$ & $4(2.3)$ & 0 \\
\hline \multicolumn{6}{|l|}{ Bronchodilator dual therapy } \\
\hline LABA+LAMA & $5(1.2)$ & $\mathrm{I}(\mathrm{I} .7)$ & $\mathrm{I}(0.9)$ & $2(1.2)$ & $\mathrm{I}(\mathrm{I} .5)$ \\
\hline \multicolumn{6}{|l|}{ Triple therapy ${ }^{\mathrm{a}}$} \\
\hline ICS/LABA+LAMA & $132(32.2)$ & $13(22.0)$ & $37(32.2)$ & $60(35.1)$ & $22(33.9)$ \\
\hline$L A M A+L A B A+I C S$ & $5(1.2)$ & 0 & $2(1.7)$ & I (0.6) & $2(3.1)$ \\
\hline \multicolumn{6}{|c|}{ ICS-based therapies not including dual LAMA+LABA component } \\
\hline ICS alone & $7(1.7)$ & $\mathrm{I}(\mathrm{I} .7)$ & $\mathrm{I}(0.9)$ & $2(1.2)$ & $3(4.6)$ \\
\hline ICS/LABA alone & $106(25.9)$ & $15(25.4)$ & $27(23.5)$ & $45(26.3)$ & $19(29.2)$ \\
\hline ICS+LAMA & $10(2.4)$ & I (I.7) & $3(2.6)$ & $4(2.3)$ & $2(3.1)$ \\
\hline ICS+LABA & $6(1.5)$ & 0 & 0 & $4(2.3)$ & $2(3.1)$ \\
\hline ICS/LABA+LABA & 0 & 0 & 0 & 0 & 0 \\
\hline ICS/LABA+LTRA & $\mathrm{I}(0.2)$ & 0 & $\mathrm{I}(0.9)$ & 0 & 0 \\
\hline ICS/LABA+xanthines & 0 & 0 & 0 & 0 & 0 \\
\hline ICS/LABA+ICS & 0 & 0 & 0 & 0 & 0 \\
\hline ICS/LABA+ICS+LTRA & 0 & 0 & 0 & 0 & 0 \\
\hline ICS/LABA+ICS+xanthines & $\mathrm{I}(0.2)$ & 0 & I (0.9) & 0 & 0 \\
\hline ICS+xanthines & $\mathrm{I}(0.2)$ & 0 & 0 & I (0.6) & 0 \\
\hline ICS+LTRA & $\mathrm{I}(0.2)$ & 0 & 0 & $\mathrm{I}(0.6)$ & 0 \\
\hline \multicolumn{6}{|l|}{ Other maintenance therapy } \\
\hline LTRA alone & 0 & 0 & 0 & 0 & 0 \\
\hline Xanthines alone & 0 & 0 & 0 & 0 & 0 \\
\hline LABA+xanthines & 0 & 0 & 0 & 0 & 0 \\
\hline ICS/LABA+LABA+LAMA & 0 & 0 & 0 & 0 & 0 \\
\hline ICS/LABA+ICS+LAMA & $\mathrm{I}(0.2)$ & 0 & 0 & 0 & $\mathrm{I}(\mathrm{I} .5)$ \\
\hline Other & $15(3.7)$ & $\mathrm{I}(\mathrm{I} .7)$ & $3(2.6)$ & $5(2.9)$ & $6(9.2)$ \\
\hline
\end{tabular}

Note: a Triple therapy defined as a single LABA, a single LAMA and a single ICS therapy only.

Abbreviations: CAT, COPD Assessment Test; COPD, chronic obstructive pulmonary disease; ICS, inhaled corticosteroid; LABA, long-acting $\beta_{2}$-agonist; LAMA, long-acting muscarinic antagonist; LTRA, leukotriene receptor antagonist; SABA, short-acting $\beta_{2}$-agonist; SAMA, short-acting muscarinic antagonist. 
Table S3 Current treatment by CAT score domain in Europe

\begin{tabular}{|c|c|c|c|c|c|}
\hline & Overall $(\mathrm{N}=1,242)$ & $0-9(n=138)$ & $10-19(n=405)$ & $20-29(n=5 \mid 2)$ & $30-40(n=187)$ \\
\hline \multicolumn{6}{|l|}{ Current treatment, $\mathrm{n}(\%)$} \\
\hline Missing, $\mathrm{n}$ & 2 & I & 0 & I & 0 \\
\hline \multicolumn{6}{|l|}{ Short-acting therapy } \\
\hline SABA, SAMA, SABA/SAMA alone & $68(5.5)$ & $19(13.9)$ & $21(5.2)$ & $23(4.5)$ & $5(2.7)$ \\
\hline \multicolumn{6}{|l|}{ Maintenance therapies } \\
\hline \multicolumn{6}{|l|}{ Bronchodilator monotherapy } \\
\hline LAMA alone & $236(19.0)$ & 45 (32.9) & $112(27.7)$ & $69(13.5)$ & $10(5.4)$ \\
\hline LABA alone & $73(5.9)$ & $16(11.7)$ & $26(6.4)$ & $25(4.9)$ & $6(3.2)$ \\
\hline \multicolumn{6}{|l|}{ Bronchodilator dual therapy } \\
\hline LABA+LAMA & $123(9.9)$ & I5 (I I.0) & $38(9.4)$ & $55(10.8)$ & $15(8.0)$ \\
\hline \multicolumn{6}{|l|}{ Triple therapy ${ }^{a}$} \\
\hline ICS/LABA+LAMA & $385(31.1)$ & $18(13.1)$ & $92(22.7)$ & $181(35.4)$ & $94(50.3)$ \\
\hline LAMA+LABA+ICS & $27(2.2)$ & $2(1.5)$ & $9(2.2)$ & II (2.2) & $5(2.7)$ \\
\hline \multicolumn{6}{|c|}{ ICS-based therapies not including dual LAMA+LABA component } \\
\hline ICS alone & $21(1.7)$ & $2(1.5)$ & $9(2.2)$ & $8(1.6)$ & $2(1.1)$ \\
\hline ICS/LABA alone & $194(15.7)$ & $15(11.0)$ & $67(16.5)$ & $86(16.8)$ & $26(13.9)$ \\
\hline ICS+LAMA & $17(1.4)$ & $\mathrm{I}(0.7)$ & $6(1.5)$ & $4(0.8)$ & $6(3.2)$ \\
\hline $\mathrm{ICS}+\mathrm{LABA}$ & $10(0.8)$ & $\mathrm{I}(0.7)$ & $2(0.5)$ & $3(0.6)$ & $4(2.1)$ \\
\hline ICS/LABA+LABA & $20(1.6)$ & $2(1.5)$ & $8(1.9)$ & $9(1.8)$ & $\mathrm{I}(0.5)$ \\
\hline ICS/LABA+LTRA & $3(0.2)$ & 0 & I (0.3) & $2(0.4)$ & 0 \\
\hline ICS/LABA+xanthines & $9(0.7)$ & I (0.7) & $\mathrm{I}(0.3)$ & $6(1.2)$ & $\mathrm{I}(0.5)$ \\
\hline ICS/LABA+ICS & 0 & 0 & 0 & 0 & 0 \\
\hline ICS/LABA+ICS+LTRA & 0 & 0 & 0 & 0 & 0 \\
\hline ICS/LABA+ICS+xanthines & 0 & 0 & 0 & 0 & 0 \\
\hline ICS+xanthines & $\mathrm{I}(0.1)$ & 0 & I (0.3) & 0 & 0 \\
\hline ICS+LTRA & 0 & 0 & 0 & 0 & 0 \\
\hline \multicolumn{6}{|l|}{ Other maintenance therapy } \\
\hline LTRA alone & $\mathrm{I}(0.1)$ & 0 & I (0.3) & 0 & 0 \\
\hline Xanthines alone & $4(0.3)$ & 0 & 0 & $4(0.8)$ & 0 \\
\hline LABA+xanthines & $\mathrm{I}(0.1)$ & 0 & 0 & $\mathrm{I}(0.2)$ & 0 \\
\hline ICS/LABA+LABA+LAMA & $9(0.7)$ & 0 & $2(0.5)$ & $6(1.2)$ & $\mathrm{I}(0.5)$ \\
\hline ICS/LABA+ICS+LAMA & $3(0.2)$ & 0 & 0 & $\mathrm{I}(0.2)$ & $2(1.1)$ \\
\hline Other & $35(2.8)$ & 0 & $9(2.2)$ & $17(3.3)$ & $9(4.8)$ \\
\hline
\end{tabular}

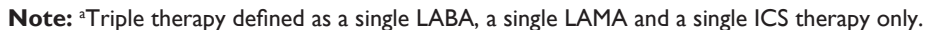

Abbreviations: CAT, COPD Assessment Test; COPD, chronic obstructive pulmonary disease; ICS, inhaled corticosteroid; LABA, long-acting $\beta_{2}$-agonist; LAMA, long-acting muscarinic antagonist; LTRA, leukotriene receptor antagonist; SABA, short-acting $\beta_{2}$-agonist; SAMA, short-acting muscarinic antagonist. 
Table S4 Current treatment by CAT score domain in China

\begin{tabular}{|c|c|c|c|c|c|}
\hline & Overall $(\mathbf{N}=5$ II) & $0-9(n=9)$ & $10-19(n=88)$ & $20-29(n=304)$ & $30-40(n=I 10)$ \\
\hline \multicolumn{6}{|l|}{ Current treatment, $\mathrm{n}(\%)$} \\
\hline Missing, $\mathrm{n}$ & I & 0 & 0 & 0 & 1 \\
\hline \multicolumn{6}{|l|}{ Single short-acting therapy } \\
\hline SABA, SAMA, SABA/SAMA alone & $19(3.7)$ & I (II.I) & $5(5.7)$ & $9(3.0)$ & $4(3.7)$ \\
\hline \multicolumn{6}{|l|}{ Maintenance therapies } \\
\hline \multicolumn{6}{|l|}{ Bronchodilator monotherapy } \\
\hline LAMA alone & $4(0.8)$ & 0 & 0 & $3(1.0)$ & $\mathrm{I}(0.9)$ \\
\hline LABA alone & $5(1.0)$ & 0 & 0 & $4(1.3)$ & $\mathrm{I}(0.9)$ \\
\hline \multicolumn{6}{|l|}{ Bronchodilator dual therapy } \\
\hline LABA+LAMA & $\mathrm{I}(0.2)$ & 0 & 0 & $\mathrm{I}(0.3)$ & 0 \\
\hline \multicolumn{6}{|l|}{ Triple therapy ${ }^{\mathrm{a}}$} \\
\hline ICS/LABA+LAMA & $8(1.6)$ & 0 & $\mathrm{I}(\mathrm{I} . \mathrm{I})$ & $2(0.7)$ & $5(4.6)$ \\
\hline LAMA+LABA+ICS & 0 & 0 & 0 & 0 & 0 \\
\hline \multicolumn{6}{|c|}{ ICS-based therapies not including dual LAMA+LABA component } \\
\hline ICS alone & II (2.2) & I (II.I) & $2(2.3)$ & $4(1.3)$ & $4(3.7)$ \\
\hline ICS/LABA alone & $132(25.9)$ & $5(55.6)$ & $15(17.0)$ & $83(27.3)$ & $29(26.6)$ \\
\hline ICS+LAMA & 0 & 0 & 0 & 0 & 0 \\
\hline ICS+LABA & $4(0.8)$ & 0 & 0 & $\mathrm{I}(0.3)$ & $3(2.8)$ \\
\hline ICS/LABA+LABA & $4(0.8)$ & 0 & 0 & $2(0.7)$ & $2(1.8)$ \\
\hline ICS/LABA+LTRA & $54(10.6)$ & 0 & $15(17.1)$ & $30(9.9)$ & $9(8.3)$ \\
\hline ICS/LABA+xanthines & $103(20.2)$ & I (II.I) & $10(11.4)$ & $70(23.0)$ & $22(20.2)$ \\
\hline ICS/LABA+ICS & $2(0.4)$ & 0 & 0 & $2(0.7)$ & 0 \\
\hline ICS/LABA+ICS+LTRA & $2(0.4)$ & 0 & $2(2.3)$ & 0 & 0 \\
\hline ICS/LABA+ICS+xanthines & $\mathrm{I}(0.2)$ & 0 & 0 & $\mathrm{I}(0.3)$ & 0 \\
\hline ICS+xanthines & $28(5.5)$ & 0 & $4(4.6)$ & $21(6.9)$ & $3(2.8)$ \\
\hline ICS+LTRA & $3(0.6)$ & 0 & $\mathrm{I}(\mathrm{I} . \mathrm{I})$ & $I(0.3)$ & $\mathrm{I}(0.9)$ \\
\hline \multicolumn{6}{|l|}{ Other maintenance therapy } \\
\hline ICS/LABA+ICS & $2(0.4)$ & 0 & 0 & $2(0.7)$ & 0 \\
\hline LTRA alone & $13(2.6)$ & 0 & $3(3.4)$ & $8(2.6)$ & $2(1.8)$ \\
\hline Xanthines alone & $57(I I .2)$ & 0 & $16(18.2)$ & $30(9.9)$ & II (I0.I) \\
\hline LABA+xanthines & $13(2.6)$ & 0 & $5(5.7)$ & $7(2.3)$ & $I(0.9)$ \\
\hline ICS/LABA+LABA+LAMA & 0 & 0 & 0 & 0 & 0 \\
\hline ICS/LABA+ICS+LAMA & 0 & 0 & 0 & 0 & 0 \\
\hline Other & $46(9.0)$ & I (II.I) & $9(10.2)$ & $25(8.2)$ & II (I0.I) \\
\hline
\end{tabular}

Note: ${ }^{a}$ Triple therapy defined as a single LABA, a single LAMA and a single ICS therapy only.

Abbreviations: CAT, COPD Assessment Test; COPD, chronic obstructive pulmonary disease; ICS, inhaled corticosteroid; LABA, long-acting $\beta_{2}$-agonist; LAMA, long-acting muscarinic antagonist; LTRA, leukotriene receptor antagonist; SABA, short-acting $\beta_{2}$-agonist; SAMA, short-acting muscarinic antagonist.

International Journal of COPD

\section{Publish your work in this journal}

The International Journal of COPD is an international, peer-reviewed journal of therapeutics and pharmacology focusing on concise rapid reporting of clinical studies and reviews in COPD. Special focus is given to the pathophysiological processes underlying the disease, intervention programs, patient focused education, and self management protocols.

\section{Dovepress}

This journal is indexed on PubMed Central, MedLine and CAS. The manuscript management system is completely online and includes a very quick and fair peer-review system, which is all easy to use. Visit http://www.dovepress.com/testimonials.php to read real quotes from published authors. 